\title{
Isolated Neutropenia: An Unexplored Side Effect of Amiodarone
}

\author{
Hiren Patel ${ }^{\mathrm{a}, \mathrm{b}}$, David Peace ${ }^{\mathrm{a}}$
}

\begin{abstract}
Amiodarone has been widely used for the treatment of various arrhythmias. It is a potent P450 inhibitor leading to interaction with many commonly prescribed drugs. Also, due to its long half-life, lipophilicity, and broad tissue distribution, it can cause a wide range of toxicities. A 62-year-old male with the unknown past medical history presented to the emergency department following a grand mal seizure. The patient initially presented with atrial flutter, which was controlled with beta blockers but was switched to amiodarone after 2 weeks when he developed atrial fibrillation with the rapid ventricular response. Approximately 1 month into his hospital stay, the patient developed severe isolated neutropenia. After ruling out other etiologies, amiodarone was withdrawn. The patient's absolute neutrophil count recovered 3 days after discontinuation of amiodarone.
\end{abstract}

Keywords: Amiodarone; AFib; Isolated neutropenia; Supratherapeutic level; Voriconazole; P450

\section{Introduction}

Amiodarone is the most effective antiarrhythmic drug for atrial and ventricular arrhythmias and the drug of choice for ventricular arrhythmias in an unstable patient. Amiodarone has been found to have higher efficacy and lower relapse rates compared to placebo and rate-control medications [1]. Despite its proven effectiveness, amiodarone has not been adopted widely, owing to frequent adverse events. More than $35 \%$ of patients on longterm amiodarone discontinue the drug due to adverse effects [2]. Some of the well-documented side effects of amiodarone are thyroid gland dysregulation, pulmonary fibrosis, and acute liver failure [3]. Additional reactions include dermal discoloration, photosensitivity, corneal depositions, and neuropathic changes such as peripheral neuritis, ataxia, tremors, and senso-

Manuscript submitted November 25, 2019, accepted December 11, 2019

aDepartment of Hematology and Oncology, University of Illinois, Chicago, IL 60607, USA

${ }^{b}$ Corresponding Author: Hiren Patel, Department of Hematology and Oncology, University of Illinois, Chicago, IL 60607, USA.

Email: shayary@gmail.com

doi: https://doi.org/10.14740/jmc3394 ry deficits [4]. Though many review articles have documented the adverse events noted above, few have described severe, potentially fatal, hematological effects. Case reports have described direct bone marrow toxicity causing granulomas and aplastic anemia [5-11].

Furthermore, amiodarone can induce immunological manifestations such as anti-amiodarone antibodies, lupus-like syndrome, immune-mediated thrombocytopenia, Coombspositive hemolytic anemia (in canines), and vasculitis [12-17]. Many medications have been implicated as causal agents of neutropenia, but only one case has been reported describing isolated neutropenia induced by amiodarone [18]. Herein, the second case of severe isolated neutropenia associated with the administration of amiodarone is discussed.

\section{Case Report}

A 62-year-old male with a history of alcohol dependence was brought to the emergency department (ED) after he was witnessed to have grand mal seizure. Before his presentation, he had been incarcerated for 2 days for "driving under the influence (DUI)". Responding medics found him to have an altered mental status, melena, coffee-ground emesis, and severe hypoglycemia with blood glucose of $24 \mathrm{mg} / \mathrm{dL}$. In the ED, the patient was reported to have a temperature of $36{ }^{\circ} \mathrm{C}$, respiratory rate $30 / \mathrm{min}$, a pulse of $138 / \mathrm{min}$, blood pressure (BP) of $62 / 36$ $\mathrm{mm} \mathrm{Hg}$, severe acute kidney injury (AKI) with electrolyte derangement (creatinine (CRE): $10.45 \mathrm{mg} / \mathrm{dL}$, blood urea nitrogen (BUN): $130 \mathrm{mg} / \mathrm{dL}$ ), liver injury (aspartate aminotransferase (AST): $173 \mathrm{IU} / \mathrm{L}$, alanine aminotransferase (ALT): 71 $\mathrm{IU} / \mathrm{L}$ ), and thrombocytopenia (platelet (PLT): $\left.10 \times 10^{3} / \mu \mathrm{L}\right)$. An electrocardiogram (EKG) showed a "non-ST segment myocardial infarction (NSTEMI)" and atrial flutter. He was started on a beta-blocker for arrhythmia, broad-spectrum antibiotics (piperacillin/tazobactam and vancomycin), three boluses of D50, and vasopressors to stabilize him. Dialysis was required to manage the AKI.

On day 2, the patient was found to have a mild pleural effusion on chest X-ray and leukocytosis with a left shift (white blood cell $(\mathrm{WBC}): 30.6 \times 10^{3} / \mu \mathrm{L}$, absolute neutrophil count (ANC): $\left.26 \times 10^{3} / \mu \mathrm{L}\right)$ despite being on antibiotics. Bronchoalveolar lavage was performed. Voriconazole was started after bronchial cultures grew Aspergillus and Candida (day 2: hemoglobin (Hb) $8.27 \mathrm{~g} / \mathrm{dL}$, PLT: $19 \times 10^{3} / \mu \mathrm{L}$, AST: $146 \mathrm{IU} / \mathrm{L}$, ALT: $78 \mathrm{IU} / \mathrm{L}, \mathrm{CRE}: 2.96 \mathrm{mg} / \mathrm{dL}, \mathrm{BUN}: 45 \mathrm{mg} / \mathrm{dL})$.

On the 15th day of his admission, the patient became un- 


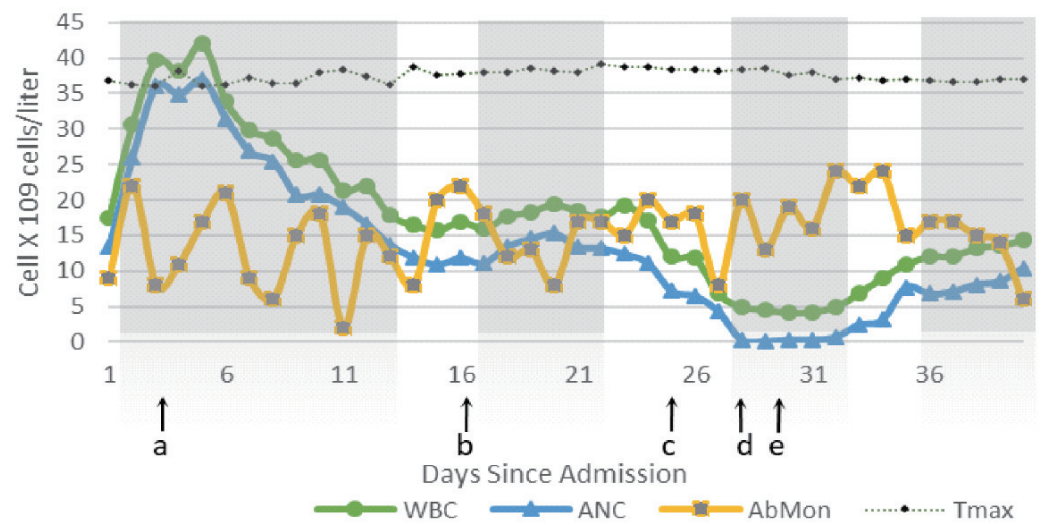

Figure 1. Changes in WBC, AbMon, ANC and temperature $\max (\operatorname{Tmax})\left({ }^{\circ} \mathrm{C}\right)$ during 40 days of hospitalization. Shaded gray areas indicate time during which patient was admitted to ICU for different reasons. a: Start of voriconazole; b: Amiodarone started; c: Vancomycin stopped; d: Onset of severe neutropenia; e: Amiodarone discontinued. Absolute monocytes (AbMon) value was multiplied by 10 to achieve a comparable value. Normal reference value of AbMon: 0.2 to $1 \times 10^{9}$ cells/L; adjusted reference AbMon value: 2 to $10 \times 10^{9}$ cells/L. WBC: white blood cell; ANC: absolute neutrophil count; ICU: intensive care unit.

stable and hypoxic (partial pressure of oxygen $\left(\mathrm{PO}_{2}\right): 59 \mathrm{~mm}$ $\mathrm{Hg}$, oxygen saturation level $\left(\mathrm{SaO}_{2}\right): 89 \%$, partial pressure of carbon dioxide $\left.\left(\mathrm{PCO}_{2}\right): 37 \mathrm{~mm} \mathrm{Hg}\right)$ after developing atrial fibrillation with a rapid ventricular response, he was intubated, and the beta-blocker was changed to amiodarone. Before initiating amiodarone, the patient's blood work was as follow: $\mathrm{Hb}$ : $7.7 \mathrm{~g} / \mathrm{dL}$, WBC: $17 \times 10^{3} / \mu \mathrm{L}$, PLT: $470 \times 10^{3} / \mu \mathrm{L}$, ANC: $13.9 \times$ $10^{3} / \mu \mathrm{L}$, absolute lymphocytes (ALym): $0.9 \times 10^{3} / \mu \mathrm{L}, \mathrm{AST}: 23$ IU/L, ALT: $15 \mathrm{IU} / \mathrm{L}$, CRE: $9.21 \mathrm{mg} / \mathrm{dL}$, BUN: $70 \mathrm{mg} / \mathrm{dL}$. The WBC count improved after $72 \mathrm{~h}$. The patient was extubated and transferred to a regular floor bed (Fig. 1).

After starting amiodarone, the patient developed frequent unexplained fevers. Fevers lasted for a short period and resolved with antipyretics. Since the fevers were not continuous, lasted short periods with no obvious cause, they were attributed to be drug-induced fevers. On day 26th, 11 days after starting amiodarone, the patient again became hemodynamically unstable and was quickly stabilized. On day 29th, daily blood report revealed $\mathrm{Hb}: 7.4 \mathrm{~g} / \mathrm{dL}, \mathrm{WBC}: 5.6 \times 10^{3 /}$ $\mu \mathrm{L}$, PLT: $378 \times 10^{3} / \mu \mathrm{L}$, ANC: $0.1 \times 10^{3} / \mu \mathrm{L}$, ALym: $2.5 \times$ $10^{3} / \mu \mathrm{L}$, absolute eosinophil (AEos): $0.2 \times 10^{3} / \mu \mathrm{L}$, absolute basophil (ABas): $0.6 \times 10^{3} / \mu \mathrm{L}, \mathrm{AST}: 15 \mathrm{IU} / \mathrm{L}, \mathrm{ALT}: 4 \mathrm{IU} / \mathrm{L}$, BUN: $18 \mathrm{mg} / \mathrm{dL}$, and CRE $6.66 \mathrm{mg} / \mathrm{dL}$. Human immunodeficiency virus (HIV), hepatitis A, B and C, Epstein-Barr virus (EBV), influenza, parvovirus $\mathrm{B} 19$, and herpes simplex virus 6 (HSV6) were ruled out. Blood cultures for bacterial and fungal infections were negative. Malnutrition as a cause of neutropenia was not evident. Since the patient was receiving multiple medications, drug-induced neutropenia (DIN) was suspected. Piperacillin/tazobactam, vancomycin, and amiodarone were the only medications that had been started within 2 weeks of the onset of neutropenia. Piperacillin/tazobactam and vancomycin had been discontinued 2 days before the onset of presumptive acute DIN. Based on the literature review, amiodarone was determined as a cause. The serum amiodarone level was found to be a supratherapeutic level at $4.57 \mu \mathrm{g} / \mathrm{mL}$. Thus, amiodarone was discontinued, and the patient was monitored closely. Within 1 week of discontinuation of amiodarone, $\mathrm{WBC}$ and $\mathrm{ANC}$ had fully recovered to $12.3 \times$ $10^{3} / \mu \mathrm{L}$ and $7.6 \times 10^{3} / \mu \mathrm{L}$, respectively (Fig. 1 ).

\section{Discussion}

Acute DIN is a reduction in absolute neutrophil count due to drugs. DIN is caused by decreased production or increased destruction of neutrophils. The American Academy of Allergy, Asthma, and Immunology defines neutropenia as mild (ANC: 1,500 to $1,000 / \mu \mathrm{L}$ ), moderate (ANC: 1,000 to $500 / \mu \mathrm{L}$ ), and severe (ANC: $<500 / \mu \mathrm{L}$ ). The prevalence of DIN is 8.9 and 7.2 cases per million every year in the USA and Europe, respectively [19-21]. Even though mortality rates have decreased from $10-16 \% 25$ years ago to less than $5 \%$, in the current era, severe neutropenia can lead to significant morbidity and death. Despite improvements in the management of agranulocytosis, protracted neutropenia still carries a risk of mortality of $9.3 \%$ and significant morbidity of $>21.4 \%$ [22-24]. Economically, each episode of neutropenia can lead to an average hospital stay of 10 days, costing upwards of $\$ 19,000$ per episode and yearly more than $\$ 1.09$ billion overall in the USA alone [22]. Keeping these statistics in mind, early detection, and intervention to patients with DIN become essential goals.

Neutropenia can also be categorized according to chronological features: acute (transient) and chronic. An ANC of < $1,500 / \mu \mathrm{L}$ for more than 3 months is considered chronic neutropenia. Nutritional deficiency of vitamin B12, folate, thiamine, and copper can lead to chronic neutropenia or agranulocytosis $[25,26]$. Though a decrease in ANC due to a nutritional deficiency is chronic in nature, considering the patient's extensive history of alcohol abuse, malnutrition was ruled out by monitoring levels of vitamins, proteins, and essential metals. Additionally, the patient was adequately nourished throughout his 28-day stay at the hospital before the onset of neutropenia.

Infections and drugs are leading causes of acute onset of neutropenia. Microorganisms such as viruses (hepatitis A, B, C; HIV, EBV, HSV6, cytomegalovirus (CMV), Pneumocystis 
carinii pneumonia (PCP)), bacteria (typhoid fever, Shigella enteritis, brucellosis, tularemia, rickettsia, tuberculosis), and parasites (Leishmania donovani and malaria) can cause neutropenia in susceptible individuals [27-31]. At the time of onset of neutropenia, the patient was also being treated for pulmonary Aspergillus, and his chest X-ray was also improving. A detailed viral panel did not reveal any pathogens in the patient. Additionally, multiple blood samples were cultured during the severe neutropenia period, and no bacterial or fungal growth was observed.

After ruling out ongoing infectious causes, possible DIN was considered. Though many drugs can lead to neutropenia, among administered medications to the patient, piperacillin/ tazobactam, vancomycin, and amiodarone were suspects. However, piperacillin/tazobactam and vancomycin had been discontinued 2 days before the onset of neutropenia. Furthermore, piperacillin/tazobactam was restarted $72 \mathrm{~h}$ after discontinuation as prophylaxis for neutropenia and was continued during the ANC recovery period (day 28 - 35).

Even though amiodarone can lead to autoimmune events, the time of onset, the serum concentration, and a quick recovery from neutropenia suggested more direct mechanisms at work $[13,17]$. In addition, studies have shown how amiodarone utilizes various mechanisms to cause direct cytotoxic effects in multiple tissues [32-35].

Amiodarone has a unique structure that allows it to form free radicals in a high oxidative environment [36-39]. Radical formation potentially explains why amiodarone most commonly damages highly oxidative environments such as lung, liver, and thyroid [40]. Neutrophils have an abundant reservoir of myeloperoxidase (MPO), which can nonspecifically oxidize amiodarone to produce aryl radicals [41]. Free radicals cause deoxyribonucleic acid (DNA) breakage, mitochondrial damage, and lipidosis giving rise to multilamellar lysosomal inclusions, which can lead to changes in morphology and function of neutrophils $[36,42]$. Due to its amphiphilic structure, amiodarone and its metabolites have wide tissue distribution. In a short period, amiodarone can reach 150 times higher concentrations in leukocytes than in plasma [43]. Additionally, our patient was concurrently receiving voriconazole, which inhibits cytochrome P450, decreases clearance, and raises the systemic concentration of amiodarone and its metabolites, further enhancing toxicity [44]. This interaction leads to an increase of amiodarone serum concentration, which was twice the upper limit of normal.

\section{Conclusions}

During his 35-day stay, even though the patient was intubated twice, resuscitated multiple times, required vasopressors frequently, and had numerous comorbidities, pieces of evidence point towards amiodarone as the cause of neutropenia. Besides isolated neutropenia, amiodarone can cause various lifethreatening hematologic conditions. Furthermore, amiodarone treatment guidelines focus primarily on monitoring lung, liver, and thyroid function. Individuals such as those with glucose6-phosphate dehydrogenase (G6PD) deficiency, polypharmacy, malnourishment, or chronic alcoholism, who are especially susceptible to oxidative damages, may be more prone to amiodarone toxicity. Thus, monitoring hematologic changes becomes an essential component of at-risk patients' care.

\section{Acknowledgments}

None to declare.

\section{Financial Disclosure}

None to declare.

\section{Conflict of Interest}

The authors declare that they have no conflicts of interest regarding the publication of this paper.

\section{Informed Consent}

Not applicable.

\section{Author Contributions}

HP gathered and organized the data related to the case study. HP and DP wrote and edited the manuscript.

\section{References}

1. Ullal AJ, Than CT, Fan J, Schmitt S, Perino AC, Kaiser DW, Heidenreich PA, et al. Amiodarone and risk of death in contemporary patients with atrial fibrillation: Findings from The Retrospective Evaluation and Assessment of Therapies in AF study. Am Heart J. 2015;170(5):10331041 e1031.

2. Bardy GH, Lee KL, Mark DB, Poole JE, Packer DL, Boineau R, Domanski M, et al. Amiodarone or an implantable cardioverter-defibrillator for congestive heart failure. N Engl J Med. 2005;352(3):225-237.

3. Shukla R, Jowett NI, Thompson DR, Pohl JE. Side effects with amiodarone therapy. Postgrad Med J. 1994; 70(825):492-498.

4. van Erven L, Schalij MJ. Amiodarone: an effective antiarrhythmic drug with unusual side effects. Heart. 2010;96(19):1593-1600.

5. Lossos IS, Matzner Y. Aplastic anemia associated with amiodarone therapy. Acta Haematol. 1992;87(4):213.

6. Bilello SJ, Bao F, Veillon DM, Muldoon R, Cotelingam JD. Pathology case of the month. Elderly man with pancytopenia. Bone marrow granulomas secondary to amiodarone. J La State Med Soc. 2006;158(1):10-12.

7. Rosenbaum H, Ben-Arie Y, Azzam ZS, Krivoy N. Amiodarone-associated granuloma in bone marrow. Ann 
Pharmacother. 1998;32(1):60-62.

8. Moran SK, Manoharan A. Amiodarone-induced bone marrow granulomas. Pathology. 2002;34(3):267-269.

9. Yamreudeewong W, McIntyre WW, Sun TJ, Ranelli PL. Bone marrow granulomas possibly associated with amiodarone. Pharmacotherapy. 2000;20(7):855-859.

10. Boutros NY, Dilly S, Bevan DH. Amiodarone-induced bone marrow granulomas. Clin Lab Haematol. 2000;22(3):167-170.

11. Erie AJ, McClure RF, Wolanskyj AP. Amiodarone-induced bone marrow granulomas: an unusual cause of reversible pancytopenia. Hematol Rep. 2010;2(1):e6.

12. Weinberger I, Rotenberg Z, Fuchs J, Ben-Sasson E, Agmon J. Amiodarone-induced thrombocytopenia. Arch Intern Med. 1987;147(4):735-736.

13. Sahud MA, Caulfield M, Clarke N, Koch R, Bougie $\mathrm{D}$, Aster R. Acute thrombocytopenia in patients treated with amiodarone is caused by antibodies specific for platelet membrane glycoproteins. Br J Haematol. 2013;163(2):260-267.

14. Staubli M, Zimmermann A, Bircher J. Amiodaroneinduced vasculitis and polyserositis. Postgrad Med J. 1985;61(713):245-247.

15. Calvert CA, Sammarco C, Pickus C. Positive Coombs' test results in two dogs treated with amiodarone. J Am Vet Med Assoc. 2000;216(12):1933-1936

16. Pichler WJ, Schindler L, Staubli M, Stadler BM, de Weck AL. Anti-amiodarone antibodies: detection and relationship to the development of side effects. Am J Med. 1988;85(2):197-202.

17. Yachoui R, Saad W. Amiodarone-induced lupus-like syndrome. Am J Ther. 2015;22(1):e20-21.

18. Groneberg DA, Barkhuizen A. Neutropenia during treatment with amiodarone. Am J Med. 2001;110(8):671.

19. Andres E, Zimmer J, Mecili M, Weitten T, Alt M, Maloisel F. Clinical presentation and management of drug-induced agranulocytosis. Expert Rev Hematol. 2011;4(2):143151.

20. Andersohn F, Konzen C, Garbe E. Systematic review: agranulocytosis induced by nonchemotherapy drugs. Ann Intern Med. 2007;146(9):657-665.

21. Strom BL, Carson JL, Schinnar R, Snyder ES, Shaw M. Descriptive epidemiology of agranulocytosis. Arch Intern Med. 1992;152(7):1475-1480.

22. Kuderer NM, Dale DC, Crawford J, Cosler LE, Lyman GH. Mortality, morbidity, and cost associated with febrile neutropenia in adult cancer patients. Cancer. 2006;106(10):2258-2266.

23. Andersen CL, Tesfa D, Siersma VD, Sandholdt H, Hasselbalch H, Bjerrum OW, Felding P, et al. Prevalence and clinical significance of neutropenia discovered in routine complete blood cell counts: a longitudinal study. J Intern Med. 2016;279(6):566-575.

24. Pick AM, Nystrom KK. Nonchemotherapy drug-induced neutropenia and agranulocytosis: could medications be the culprit? J Pharm Pract. 2014;27(5):447-452.

25. Gibson C, Berliner N. How we evaluate and treat neutropenia in adults. Blood. 2014;124(8):1251-1258; quiz 1378.
26. Dunlap WM, James GW, 3rd, Hume DM. Anemia and neutropenia caused by copper deficiency. Ann Intern Med. 1974;80(4):470-476.

27. Mallouh AA, Sa'di AR. White blood cells and bone marrow in typhoid fever. Pediatr Infect Dis J. 1987;6(6):527529.

28. al-Eissa Y, al-Nasser M. Haematological manifestations of childhood brucellosis. Infection. 1993;21(1):23-26.

29. Dale DC, Wolff SM. Studies of the neutropenia of acute malaria. Blood. 1973;41(2):197-206.

30. Marwaha N, Sarode R, Gupta RK, Garewal G, Dash S. Clinico-hematological characteristics in patients with kala azar. A study from north-west India. Trop Geogr Med. 1991;43(4):357-362.

31. Newburger PE, Dale DC. Evaluation and management of patients with isolated neutropenia. Semin Hematol. 2013;50(3):198-206.

32. Piccotti JR, LaGattuta MS, Knight SA, Gonzales AJ, Bleavins MR. Induction of apoptosis by cationic amphiphilic drugs amiodarone and imipramine. Drug Chem Toxicol. 2005;28(1):117-133.

33. Di Matola T, D'Ascoli F, Fenzi G, Rossi G, Martino E, Bogazzi F, Vitale M. Amiodarone induces cytochrome $\mathrm{c}$ release and apoptosis through an iodine-independent mechanism. J Clin Endocrinol Metab. 2000;85(11):43234330.

34. Martin WJ, 2nd, Rosenow EC, 3rd. Amiodarone pulmonary toxicity. Recognition and pathogenesis (Part I). Chest. 1988;93(5):1067-1075.

35. Martin WJ, 2nd, Rosenow EC, 3rd. Amiodarone pulmonary toxicity. Recognition and pathogenesis (Part 2). Chest. 1988;93(6):1242-1248.

36. Nicolescu AC, Comeau JL, Hill BC, Bedard LL, Takahashi T, Brien JF, Racz WJ, et al. Aryl radical involvement in amiodarone-induced pulmonary toxicity: investigation of protection by spin-trapping nitrones. Toxicol Appl Pharmacol. 2007;220(1):60-71.

37. Paillous N, Verrier M. Photolysis of amiodarone, an antiarrhythmic drug. Photochem Photobiol. 1988;47(3):337343.

38. Ozkaya AK, Dilber E, Gurgen SG, Kutlu O, Cansu A, Gedik Y. Effects of chronic amiodarone treatment on rat testis. Acta Histochem. 2016;118(3):271-277.

39. Waring JF, Jolly RA, Ciurlionis R, Lum PY, Praestgaard JT, Morfitt DC, Buratto B, et al. Clustering of hepatotoxins based on mechanism of toxicity using gene expression profiles. Toxicol Appl Pharmacol. 2001;175(1):28-42.

40. Tesfa D, Keisu M, Palmblad J. Idiosyncratic drug-induced agranulocytosis: possible mechanisms and management. Am J Hematol. 2009;84(7):428-434.

41. Reasor MJ, Kacew S. An evaluation of possible mechanisms underlying amiodarone-induced pulmonary toxicity. Proc Soc Exp Biol Med. 1996;212(4):297-304.

42. Adams PC, Sloan P, Morley AR, Holt DW. Peripheral neutrophil inclusions in amiodarone treated patients. Br J Clin Pharmacol. 1986;22(6):736-738.

43. Dake MD, Madison JM, Montgomery CK, Shellito JE, Hinchcliffe WA, Winkler ML, Bainton DF. Electron microscopic demonstration of lysosomal inclusion bodies 
in lung, liver, lymph nodes, and blood leukocytes of patients with amiodarone pulmonary toxicity. Am J Med. 1985;78(3):506-512.

44. Jeong S, Nguyen PD, Desta Z. Comprehensive in vitro analysis of voriconazole inhibition of eight cytochrome P450 (CYP) enzymes: major effect on CYPs 2B6, 2C9, 2C19, and 3A. Antimicrob Agents Chemother. 2009;53(2):541-551. 